\title{
ЭФФЕКТИВНОСТЬ ТЕХНОЛОГИИ
} ПРИПОВЕРХНОСТНОГО ПОЛИВА

\section{МНОГООПОРНЫМИ ДОЖДЕВАЛЬНЫМИ МАШИНАМИ КРУГОВОГО ДЕЙСТВИЯ}

\author{
EFFICIENCY OF SURFACE TECHNOLOGY \\ MULTI-SHOULDER RAINING CIRCULAR MACHINES
}

\author{
Н.Ф. Рыжко, доктор технических наук, \\ Н.В. Рыжко, \\ С.Н. Рыжко, \\ Е.А. Шишенин
}

Волжский научно-исследовательский институт гидротехники и мелиорации

\author{
N.F. Ryzhko, doctor of technical sciences, \\ N.V. Ryzhko, \\ S.N. Ryzhko, \\ E.A. Shishenin
}

Volga Scientific-Research Institute of Hydraulic Engineering and Land Reclamation
Проведен анализ агротехнических показателей полива современных многоопорных дождевальных машин вантовой и ферменной конструкции отечественного и иностранного производства и определены основные направления их дальнейшего совершенствования для улучшения качества полива. Приведено описание усовершенствованного устройства приповерхностного полива для дождевальных машин вантовой конструкции типа «Фрегат», которое отличается простотой конструкции и изготовления, обеспечивает легкое регулирование высоты установки дождевальной насадки - в пределах 1,0-2,2 м от поверхности почвы по мере роста сельхозкультур. Разработано три варианта устройства приповерхностного полива для дождевальных машин ферменной конструкции типа «Кубань». Устройства приповерхностного полива первого варианта снижают высоту установки дождевальной насадки с 4,0-4,5 м до нижнего шпренгельного пояса (2,7 м от поверхности почвы). Устройства приповерхностного полива второго и третьего вариантов обеспечивают регулирование высоты установки дождевальной насадки от 1,0 до 2,7 м. Устройства приповерхностного полива первого и второго вариантов обеспечивают увеличение ширины расстановки дождевальных насадок относительно трубопровода до 2,5 м, а третьего варианта - до 5,0-6,0 м, что снижает среднюю интенсивность дождя на 25-35\%. Приведены конструкции усовершенствованной дефлекторной насадки и дождевальной насадки со съемным дефлектором, которые формируют мелкокапельный дождь и снижают вероятность засорения мусором. Доказано, что устройства приповерхностного полива снижают потери воды на испарение и снос ветром на 10$15 \%$, а также повышают равномерность полива при скорости ветра 3-4 м/с с 0,50-0,60 до 0,70-0,75. Применение устройств приповерхностного полива обеспечивает увеличение ширины захвата дождем и снижает интенсивность дождя на 15$35 \%$, что в совокупности со снижением потерь воды на испарение и повышением равномерности полива обеспечивает увеличение урожайности сельскохозяйственных культур на 12-36\%. Усовершенствованные устройства приповерхностного полива для ДМ «Фрегат» и «Кубань» окупаются в первый год эксплуатации.
The analysis of agrotechnical indicators of irrigation of modern multi-support irrigation machines of cable-stayed design and truss design of domestic and foreign production is made and the main directions of their further improvement of the irrigation quality are determined. A description of an improved device for near-surface irrigation for sprinkler machines of a cable-stayed design «Frigate» is given; this device is distinguished by its simplicity of manufacturing and design, provides easy control of the height of the sprinkler nozzle installation - within 1.0-2.2 m from the soil surface as crops grow. Three variants of near-surface irrigation device for truss irrigation machines of the Kuban type have been developed. The near-surface irrigation device of the first option reduces the installation height of the sprinkler nozzle from 4.0-4.5 $\mathrm{m}$ to the lower truss belt ( $2.7 \mathrm{~m}$ from the soil surface). The surface irrigation devices according to the second and third options provides adjustment of the installation height of the sprinkler nozzle from 1.0 to $2.7 \mathrm{~m}$. Near-surface irrigation devices (the first and the second options) provide an increase in the width of the sprinkler nozzles relative to the pipeline up to $2.5 \mathrm{~m}$, and in the third option - up to 5.0-6.0 m, which reduces the average rain intensity by $25-35 \%$. Designs of an improved deflector nozzle and a sprinkler nozzle with a removable deflector are presented, which form a small drop of rain and reduce the chance of clogging with garbage. Researches confirm that surface irrigation devices reduce water loss due to evaporation and wind drift by $10-15 \%$, and also increase the uniformity of irrigation at a wind speed of 3-4 $\mathrm{m} / \mathrm{s}$ from $0.50-0.60$ to $0.70-0.75$. The use of near-surface irrigation devices provides an increase in the width of rain and reduces the intensity of rain by $15-35 \%$, which, combined with a decrease in water loss by evaporation and an increase in the uniformity of irrigation, increase the yield of crops. Improved near-surface irrigation devices for "Frigate" and "Kuban" sprinkling machines pay off in the first year of operation. 
Ключевые слова: дождевальные машины, устройства приповерхностного полива, дождевальные насадки, потери воды на испарение и снос, равномерность полива, интенсивность дождя, эффективность полива

Введение. В Российской Федерации продолжается интенсивное восстановление мелиорируемых земель. За период с 2014 по 2020 годы планируется ввести в эксплуатацию 594,7 тыс. га [12]. Многоопорные дождевальные машины (ДМ) являются основными в мелиоративном комплексе, обеспечивая полив порядка $56 \%$ орошаемых земель $[3,5,6]$. В нашей стране эксплуатируется большое количество современных ДМ «Фрегат» и «Кубань», которые обеспечивают полив в автоматическом режиме. В последние годы стали широко внедряться иностранные электрифицированные многоопорные ДМ - Zimmatic, Valley, Bauer, T-L и новые аналогичные машины российского производства - «Каскад», «Орсис», «Казанка», «Ахтуба» и другие [2].

Работы по совершенствованию дождевальных машин вантовой конструкции типа «Фрегат» проводятся в 000 БСГ, «Корвет» - в 000 «Самарский ЗСМ», «Волга-СМ»- в 000 «АгроТехСервис» и ВолжНИИГиМ.

При эксплуатации многоопорных дождевальных машин важно соблюдать почвоохранные и водосберегающие технологии орошения для сохранения плодородия почв и снижения потребления водных ресурсов [3].

Анализ эксплуатации ДМ «Фрегат» показывает, что большинство из них не обеспечивают необходимую равномерность полива. Это объясняется отсутствием точной настройки дефлекторных насадок на требуемые расход воды и режим распыла струй. В рядовых условиях эксплуатации коэффициент эффективного полива обычно находится в пределах 0,35-0,53 [4]. В первой половине трубопровода ДМ «Фрегат» в основном монтируются дефлекторные насадки с соплом большого диаметра, что приводит к переполиву, инфильтрационным потерям, образованию глубокой колеи и может вызывать буксование первых тележек машины. Во второй половине трубопровода ДМ «Фрегат» наблюдается падение давления до величины ниже требуемой, при этом уменьшается расход воды насадок, что приводит к недополиву. Также снижается распыл струй, что ухудшает качественные показатели полива. При поливе оросительной водой повышенной засоренности наблюдается частое засорение сопел дождевателей, что снижает равномерность полива машины. Высота подъема дождевого облака над ДМ «Фрегат» составляет 4,5-7,0 м, что приводит к значительным потерям оросительной воды (10-15\%) на испарение и снос ветром, которые в жаркие и ветреные дни увеличиваются до 20\% и более. Известные устройства приповерхностного полива для ДМ «Фрегат» име[11]. туальными.
Key words: sprinkling machines, near-surface irrigation devices, irrigation nozzles, evaporation and wind blow water loss, uniformity of irrigation, rain intensity, irrigation efficiency ют большую металлоемкость, трудно регулируются в результате значительной коррозии резьбовых соединений и не позволяют существенно увеличить ширину расстановки насадок относительно трубопровода машины.

Для ДМ «Кубань» характерным является расположение насадок на высоте 4,0-4,5 м от поверхности почвы, при этом высота подъема дождевого облака достигает 5,5-6,0 м, что приводит к значительному сносу дождя и увеличению потерь воды на испарение и снос ветром

На электрифицированных многоопорных дождевальных машинах зарубежного производства (Zimmatic, Valley, Bauer, T-L) используются устройства приповерхностного дождевания (полива), которые представляют собой свисающие напорные рукава, на нижнем конце которых устанавливаются регуляторы давления и дождевальные насадки типа i-wob или Nelson. Такие насадки, как правило, работают при небольшом давлении (1015 psi) и формируют крупнокапельный дождь большой удельной мощности, что не позволяет выдавать оптимальные поливные нормы без стока.

Поэтому работы по повышению равномерности и качества полива многоопорных дождевальных машин являются ак-

Цель данных научных исследований - модернизация многоопорных дождевальных машин для обеспечения почвоохранных и водосберегающих технологий орошения.

Материалы и методы. Исследования по эффективности технологии приповерхностного дождевания при поливе
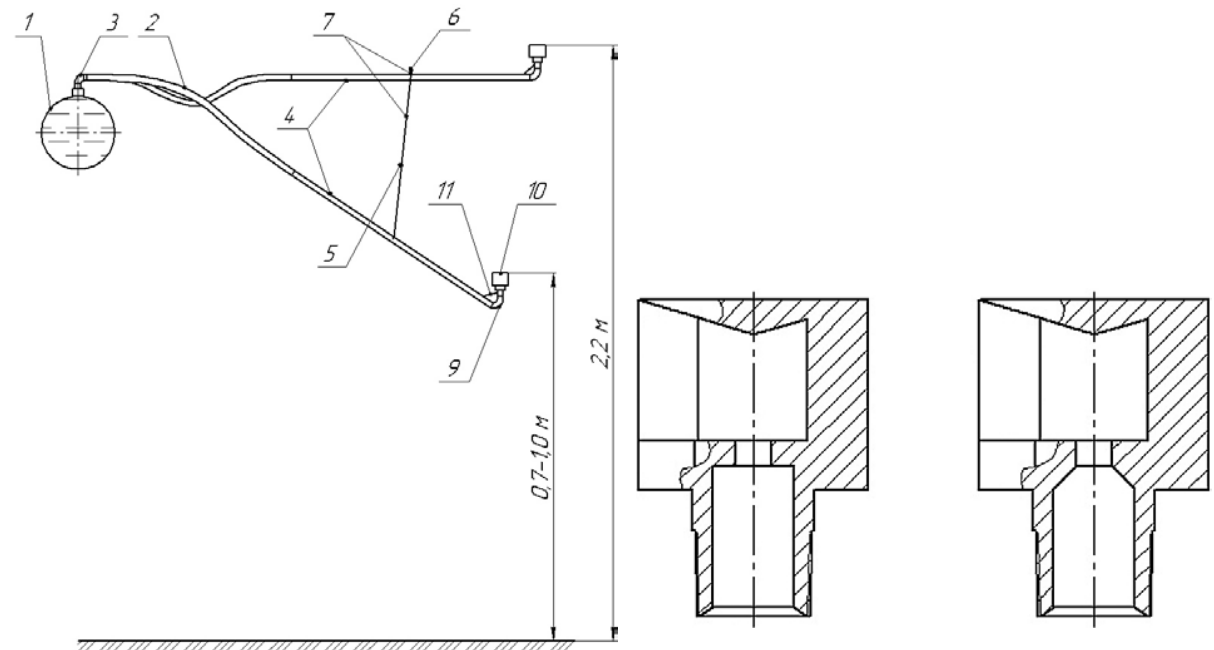

a B 
полость с конусом (рисунок 1в) (угол конуса $-\gamma=150-1600$ ), при этом сопло имеет средний коэффициент расхода воды: $\mu$ $=0,80-0,82[7]$.

Также были разработаны устройства приповерхностного полива (три варианта) для машин ферменной конструкции (рисунок 2), которые позволяют увеличить ширину захвата дождем и одновременно снизить его среднюю интенсивность. Это достигается путем замены секторных насадок, монтируемых на трубопроводе ДМ «Кубань-ЛК» на высоте 4,5 м, на дождевальные насадки со съемным дефлектором (рисунок 2б), устанавливаемые на шпренгелях фермы на высоте 2,7 м от поверхности почвы (рисунок 2, вариант 1).

Монтаж дождевальных насадок на высоте 0,8-1,0 м на шпренгелях фермы может осуществляться с использованием рукавов (рисунок 2, вариант 2) или кронштейнов, или штанг (рисунок 2 , вариант 3 , [1]). Усовершенствованные устройства приповерхностного полива увеличивают расстояние между насадками до 2,5 м (рисунок 2, вариант 2) и до 5-6 м (рисунок 2, вариант 3). Средняя интенсивность дождя в опыте уменьшалась на $25-35 \%$.

Исследования стандартной ДМ Zimmatic в 000 «Липовское» на посевах люцерны показали, что увеличение мощности дождя в концевой части машины до 0,180 Вт/м² влечет образование луж на поле и перераспределение дождя по элементам рельефа. Замеры высоты люцерны и анализ урожайности показали, что на участке поля, расположенном в концевой части машины, где мощность дождя большая, наблюдалась значительная пестрота урожая, коэффициент вариации составил 12,80-15,20\% при средней высоте растений 47,543,0 см (таблица 1).

По мере снижения мощности дождя коэффициент вариации высоты растений уменьшался, а средняя высота растений на пролете между тележками 2 и 3 увеличивалась до 58,90 см. При этом урожайность люцерны на участке поля, расположенном в концевой части маши-
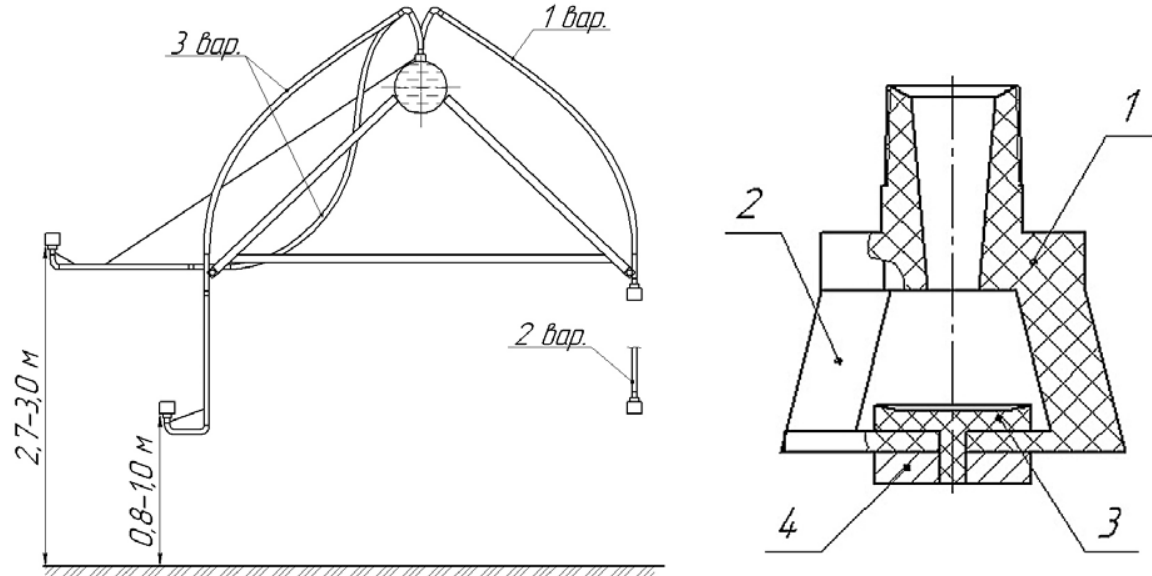

a

б

Рисунок 2 - Схема устройства приповерхностного полива для машин ферменной конструкции (варианты 1-3)

ны, орошаемом дождем значительной мощности, существенно уменьшилась на $36,9 \%$.

Усовершенствованные дождевальные насадки (рисунок 1, 2) формировали эрозионно безопасный дождь, у которого при оптимальном давлении средний диаметр капель был в 1,5 раза меньше по сравнению со значением диаметра капель, формируемых дождевателями i-wob и Nelson, работающих при малом давлении - 10-15 psi.

Полевые исследования подтвердили, что устройства приповерхностного полива снижают потери воды на испарение и снос ветром на $10-15 \%$, повышают равномерность полива при ветре 3-4 м/с с $0,50-0,60$ до $0,70-0,75$ и способствуют увеличению урожайности сельскохозяйственных культур на $12-36 \%[8,9,10]$.

Заключение. Разработаны и внедрены два вида дождевальных насадок с неподвижным и съемным дефлекторами, которые формируют мелкокапельный и ветроустойчивый дождь, а также снижают вероятность засорения мусором.

Разработаны усовершенствованные устройства приповерхностного полива для дождевальных машин вантовой и ферменной конструкции, которые отличаются простотой изготовления и легкостью в регулировке высоты установки насадки, минимизируют гидравлические потери и обеспечивают полный слив воды после отключения дождевальной машины.

Увеличение ширины захвата дождем и снижение его мощности обеспечивают улучшение качественных показателей полива: снижение интенсивности дождя (на 15-35\%), уменьшение потерь воды на испарение и снос ветром (на 10-15\%), повышение равномерности увлажнения почвы (на 12\%).

Оптимизация параметров полива способствует увеличению урожайности сельскохозяйственных культур (на 12-36\%).

Таблица 1 - Изменение высоты растений люцерны и коэффициента вариации вдоль трубопровода ДМ Zimmatic

\begin{tabular}{|c|c|c|c|c|}
\hline $\begin{array}{c}\text { Показатель характеристики полива } \\
\text { и высота люцерны }\end{array}$ & Тележки 2-3 & Тележки 4-5 & Тележки 7-8 & $\begin{array}{c}\text { Тележка 8 } \\
\text {-консоль }\end{array}$ \\
\hline Интенсивность дождя, мм/мин & 0,45 & 0,60 & 1,05 & 0,176 \\
\hline Мощность дождя, Вт/м & 0,054 & 0,106 & 47,5 & 43,0 \\
\hline Средняя высота люцерны, см & 58,9 & 56,5 & 180 \\
\hline Коэффициент вариации, \% & 3,56 & 4,85 & 15,20 \\
\hline
\end{tabular}




\section{Библиографический список}

1. Дождевальная машина: пат. 184629, Российская Федерация: МПК A01G 25/09 / Н.Ф. Рыжко, И.А. Шушпанов, А.С. Горбачев, Ю.А. Гопкалов [и др.]; опубл. 10.02.2016, Бюл. №4.

2. Мелихов, В.В. Мелиорация сельскохозяйственных земель России - стратегия и тактика системного развития / В.В. Мелихов // Орошаемое земледелие. - 2017. - №4. - С. 3-4.

3. Ресурсосберегающие энергоэффективные экологически безопасные технологии и технические орошения: справочник / Г.В. Ольгаренко [и др.]; под ред. Г.В. Ольгаренко. - М.: ФГБНУ «Росинформагротех», 2015. - 264 с.

4. Рыжко, Н.Ф. Модернизация устройств приповерхностного дождевания для ДМ «Фрегат» / Н.Ф. Рыжко, С.Н. Рыжко, О.В Карпова, С.В. Ботов // Инновационные агро- и биотехнологии в адаптивно-ландшафтном земледелии на мелиорированных землях: сб. науч. тр. / ФГБНУ ВНИИМЗ. - Тверь, 2016. - С. 247 251.

5. Рыжко, Н.Ф. Обоснование ресурсосберегающего дождевания и совершенствование дождевальных машин «Фрегат» в условиях Саратовского Заволжья: дис. ...док. техн. наук: 06.01.02 защищена 25.05.12 / Н.Ф. Рыжко. - Саратов, 2012. - 356 с.

6. Рыжко, Н.Ф. Совершенствование дождеобразующих устройств для многоопорных дождевальных машин / Н.Ф Рыжко. - Саратов: ФГОУ ВПО Саратовский ГАУ, 2009. - 176 с.

7. Рыжко, Н.Ф. Совершенствование оборудования приземного полива ДМ «Фрегат» / Н.Ф. Рыжко, Е.С. Смирнов, С.В. Ботов // Инновационные достижения науки и техники АПК: сб. науч. тр. / ФГБОУ ВО Самарский ГАУ. - Кинель, 2019. - С. 444-448.

8. Рыжко, С.Н. Усовершенствование устройств приповерхностного дождевания для ДМ «Фрегат» и их экономическая эффективность / С.Н. Рыжко, О.В. Карпова, С.А. Хорин, Н.Ф. Рыжко // Пути повышения эффективности орошаемого земледелия. - 2016. - №3 (63). - С. 107-111.

9. Рыжко, Н.Ф. Эффективность технологии приповерхностного полива на ДМ «Фрегат» / Н.Ф. Рыжко, С.Н. Рыжко, Н.В. Рыжко, С.В. Ботов, С.А. Хорин // Вестник мелиоративной науки. - 2018. - №1. - С. 57-60.

10. Соловьев, Д.А. Совершенствование устройств приповерхностного дождевания для ДМ «Фрегат» / Д.А. Соловьев, О.В Карпова, Н.Ф. Рыжко, С.Н. Рыжко // Аграрный научный журнал. - 2016. - №3. - С.65-68.

11. Чубиков, Н.Е. Исследование и внедрение технологии приповерхностного дождевания / Н.Е. Чубиков, Н.Ф. Рыжко, В.Л. УГнавый, И.А. Шушпанов / Технические, технологические и экологические проблемы орошения земель Поволжья: сб. науч. тр. / ФГНУ ВолжНИИГиМ; под ред. В.А. Нагорного [и др.] - Саратов, 2006. - С. 34-38.

12. Федеральная целевая программа «Развитие мелиорации земель сельскохозяйственного назначения России на 20142020 годы» [Эл. pесурс] - Режим доступа: http://pravo.gov.ru/ proxy/ips/?docbody=\&nd=102168535\&rdk=\&backlink=1 (дата обращения 27.02.2020).

\section{Дополнительные сведения об авторах:}

Николай Федорович Рыжко, главный научный сотрудник отдела модернизации технических средств и технологии полива, volzniigim@bk.ru,

Наталья Васильевна Рыжко, старший научный сотрудник отдела модернизации технических средств и технологии полива, volzniigim@bk.ru,

Сергей Николаевич Рыжко, младший научный сотрудник отдела модернизации технических средств и технологии полива, volzniigim@bk.ru,

Евгений Александрович Шишенин, младший научный сотрудник отдела модернизации технических средств и технологии полива, volzniigim@bk.ru
Bibliographic list

1. Sprinkling machine: Pat. 184629, Russian Federation: IPC AOG 25/09 / N.F. Ryzhko, I.A. Shushpanov, A.S. Gorbachev, Yu.A. Gopkalov [et al.]; publ. 02.10.2016, Bull. No4.

2. Melikhov, V.V. Reclamation of agricultural lands of Russia - strategy and tactics of system development / V.V. Melikhov // Irrigated agriculture. - 2017. - No.4. - P. 3-4.

3. Resource-saving energy-efficient environmentally friendly technologies and technical irrigation: a guide. / G.V. Olgarenko [et al.]; ed. G.V. Olgarenko. - M.: Federal State Budgetary Institution "Rosinformagroteh", 2015. - 264 p.

4. Ryzhko, N.F. Modernization of near-surface irrigation devices for DM "Frigate" / N.F. Ryzhko, S.N. Ryzhko, O.V. Karpova, S.V. Botov // Innovative agro- and biotechnologies in adaptive landscape farming on reclaimed lands: Sat. scientific tr. / FSBI VNIIMZ. - Tver, 2016. - P. 247-251.

5. Ryzhko, N.F. Justification of resource-saving sprinkling and improvement of the "Frigate" sprinkler machines in the conditions of the Saratov Trans-Volga region: diss. ... Dr. tech. Sciences: 01.06.02: protected on 05.25.12 / N.F. Ryzhko. - Saratov, 2012. $356 \mathrm{p}$.

6. Ryzhko, N.F. Improvement of rain-forming devices for multibearing sprinkling machines / N.F. Ryzhko. - Saratov: Federal State Educational Institution of Higher Professional Education Saratov State Agrarian University, 2009. - 176 p.

7. Ryzhko, N.F. Improvement of surface irrigation equipment DM "Frigate" / N.F. Ryzhko, E.S. Smirnov, S.V. Botov // Innovative achievements of science and technology of the agro-industrial complex: Sat. scientific tr. / FSBEI HE Samara State Agrarian University. - Kinel, 2019. - P. 444-448.

8. Ryzhko, S.N. Improvement of near-surface irrigation devices for DM "Frigate" and their economic efficiency / S.N. Ryzhko, O.V. Karpova, S.A. Khorin, N.F. Ryzhko // Ways to improve the efficiency of irrigated agriculture. - 2016. - No.3 (63). - P. 107-111.

9. Ryzhko, N.F. The effectiveness of surface irrigation technology at DM "Frigate" / N.F. Ryzhko, S.N. Ryzhko, N.V. Ryzhko, S.V. Botov, S.A. Khorin // Bulletin of reclamation science. - 2018. - No.1. - P. 57-60.

10. Soloviev, D.A. Improvement of near-surface irrigation devices for DM "Frigate" / D.A. Soloviev, O.V. Karpova, N.F. Ryzhko, S.N. Ryzhko // Agrarian scientific journal. - 2016. - No.3. - P. 65-68.

11. Chubikov, N.E. Research and implementation of surface irrigation technology / N.E. Chubikov, N.F. Ryzhko, V.L. Ognavy, I.A. Shushpanov / Technical, technological and environmental problems of irrigation of the Volga lands: Sat. scientific tr. / Federal State Institution "VolzhNIIIGiM"; Ed. V.A. Nagorny [et al.]. - Saratov, 2006. - P. 34-38.

12. The federal target program "Development of land reclamation of agricultural lands of Russia for 2014-2020" [El. resource] - Access mode: http://pravo.gov.ru/proxy/ ips $/$ docbody $=\&$ nd $=102168535 \& \mathrm{rdk}=\&$ backlink=1 (accessed date 02.27.2020).

\section{Additional information about the authors:}

Nikolay Fedorovich Ryzhko, chief researcher of department of modernization of technical equipment and irrigation technology volzniigim@bk.ru,

Natalia Vasilyevna Ryzhko, senior researching of department of modernization of technical equipment and irrigation technology, volzniigim@bk.ru,

Sergey Nikolaevich Ryzhko, junior researcher of department of modernization of technical equipment and irrigation technology, volzniigim@bk.ru,

Evgeny Aleksandrovich Shishenin, junior researcher of department of modernization of technical equipment and irrigation technology, volzniigim@bk.ru 